\title{
The Discovery of Calcite Intrinsic Wettability by the First-Ever Optical Illumination Inside Dark Fluid using IRIDW Apparatus
}

\author{
Omar Alfarisi, Aikifa Raza, TieJun Zhang
}

\begin{abstract}
Wettability is one of the critical physical-chemical properties controlling multiphase flow in porous media. Therefore, it is vital to identify the wettability for each rock type when building 3D geological models for predicting the fluid flow behavior using a numerical simulator. Wettability-unique relative permeability curves are part of each flow simulator's rock type for proper simulation predictions. The reference approach for wettability determination is contact angle measurement. The literature recoded the wettability of contact angle measurement inside transparent fluid like water and decane. However, we need to visualize and measure the water-rock contact angle inside dark fluid like the hydrocarbon. We propose visualizing and measuring the wettability contact angle for rock-water inside dark hydrocarbon fluid. We use the Illumination through Rock Inside Dark fluid for Wettability measurement (IRIDW) apparatus.
\end{abstract}

\section{Introduction}

Each 3D geological grid block [1-3] requires a rock type [4-8] with physical and chemical properties [9, 10] like lithology [11, 12], porosity, permeability, capillary pressure [13-30], fluid saturation[31-39], relative permeability [40], and wettability[41, 42]. Wettability is one of the main controlling attributes of fluid flow in porous media. However, most of the used wettability values are assumption-dependent rather than in-situ intrinsic rock values. Method unavailability for measuring surface wettability inside dark hydrocarbon fluid is one reason for Figure 1. Carbonate rock holds heterogeneous morphology [43], making measuring the rock surface wettability complex. Therefore, to solve the heterogeneous carbonate wettability, understanding the intrinsic wettability of calcite is vital.

Researchers worked on several methods for quantifying wettability in water and hydrocarbon-bearing formations using experimentation and numerical simulation. Experiment-based measurements include static and dynamic processes. The static process visually measures Contact Angle (CA) between a fluid and solid emersed in a second fluid. The CA method is the reference method for all others. Dynamic processes deliver a wettability index using flooding cycles containing alternating forced and spontaneous flow. On the other hand, the simulation methods include mainly Lattice Boltzmann flow simulation [41] and quantum simulation [44]. 
Inside dark hydrocarbon, engineers and scientists couldn't use CA to measure wettability because of invisibility. Hence, all rock typing approaches lack the related physical and chemical properties at the true wettability. Therefore, engineers assume several wettability conditions for determining the permeability, capillary pressure, and relative permeability (i.e., water wet, mixed wet, or hydrocarbon wet). In contrast, the proper determination would consider the insitu wettability for each rock at the actual depth below sea level. However, the wettability in hydrocarbon-bearing zones is unavailable due to the contact angle invisibility. We propose wettability determination using the Illumination through Rock Inside Dark fluid for Wettability measurement (IRIDW).

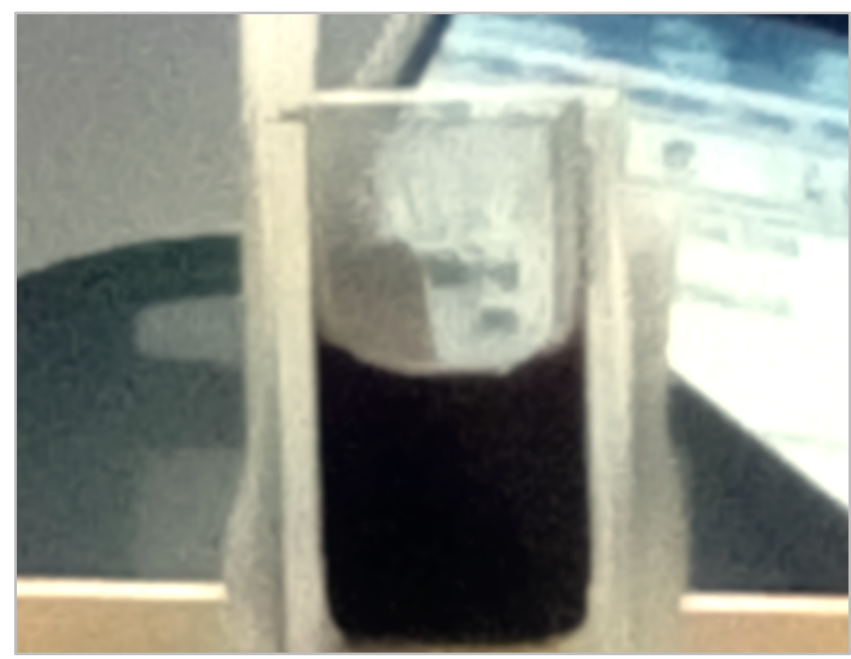

Figure 1. Dark fluid (hydrocarbon) has a calcite rock and water droplet inside; however, everything is invisible.

\section{Method}

The IRIDW apparatus consists of two light sources, a metal stage with a hole, a glass beaker, and a camera, Figure 2. The first light source forms $180^{\circ}$ with the camera, representing a standard CA measurement setup. However, the second light source under the metal stage, which creates $90^{\circ}$ with the camera, is one of the novel additions to the standard apparatus. In Figure 1, the first light source illuminates the glass beaker alone, without using the second source, where all the beaker emersed calcite rock and water droplet contents are invisible. We propose creating a path for light photons to reach the calcite rock and the water droplet to illuminate them in a dark hydrocarbon fluid. As shown in Figure 2, we added a second light source below the metal stand. We have a hole in that metal stand, enabling the light photons to pass through the hole and reach the glass beaker containing the calcite rock, water droplet, and dark hydrocarbon fluid. The light photons continue their path inside the calcite rock to illuminate it and continue further to illuminate the water droplet. The camera position in Figure 2 is the same place as Figure 1. 


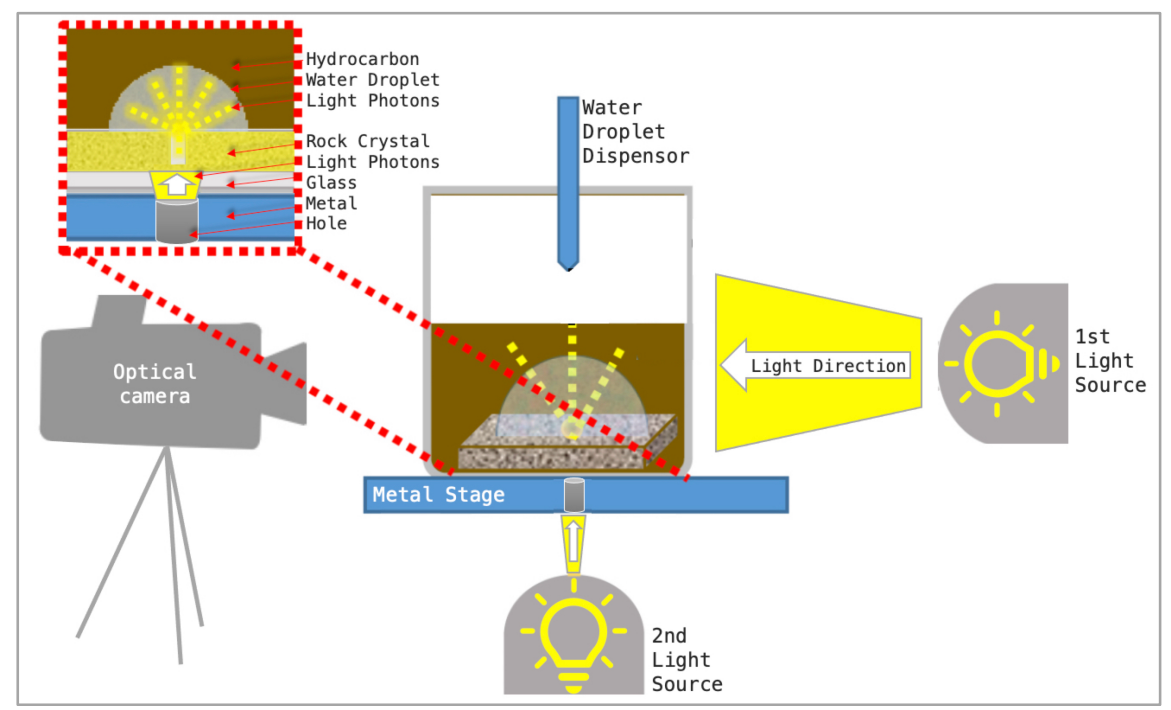

Figure 2. Novel wettability measurement apparatus (IRIDW) visualizes the emersed calcite and water droplet inside dark hydrocarbon.

\section{Result and Discussion}

Once we apply the novel setup of IRIDW shown in Figure 2, we can see the contact angle of a water droplet on calcite rock for the first time inside a dark hydrocarbon fluid, Figure 3. This visualization marks the discovery of calcite surface wettability inside hydrocarbon as the first reference for further experimentation using IRIDW.

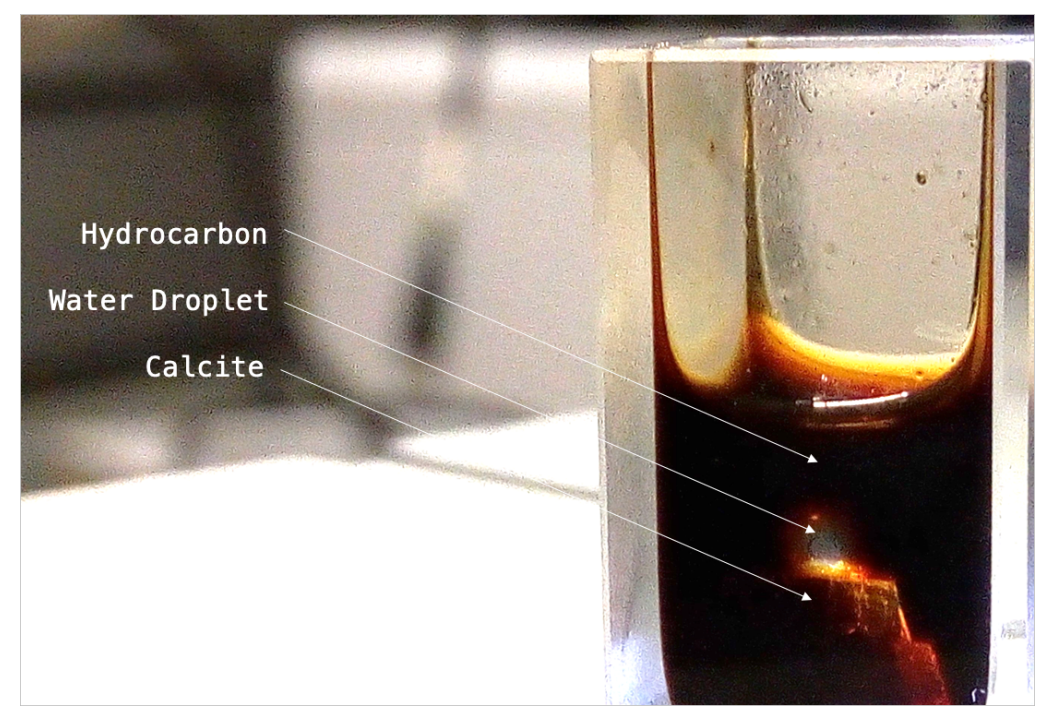

Figure 3. The first record of an illuminated water droplet on top of calcite rock inside dark hydrocarbon fluid, using IRIDW.

For a visual comparison of the dark hydrocarbon-bearing glass beaker in two different measuring apparatus, we display Figure 4. The left-side image of Figure 4 shows the pictured dark hydrocarbon-bearing glass beaker without the IRIDW apparatus. In contrast, we record the right-side image of Figure 4 with IRIDW to see what is inside the dark hydrocarbon-bearing glass beaker. 


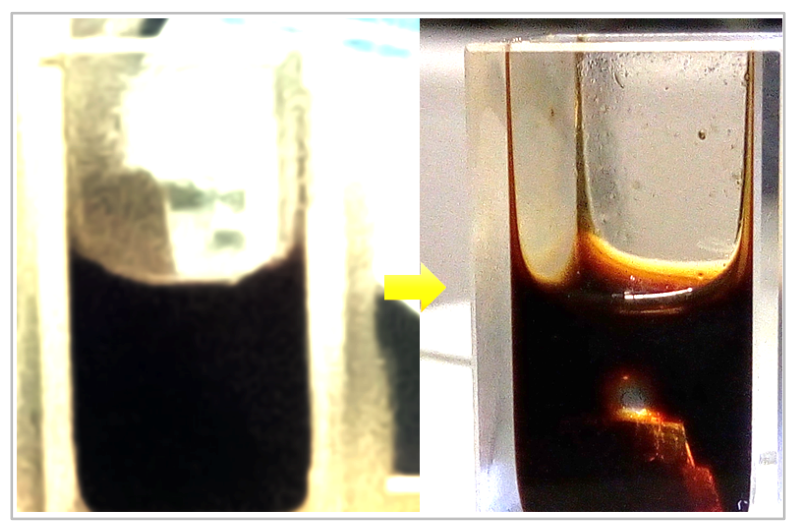

Figure 4. Comparing the glass beaker image (left) without using IRIDW and the appearance of the same beaker after using IRIDW setup (right), showing the firstever image of a water droplet on top of calcite rock inside dark hydrocarbon fluid.

When we magnify Figure 3, the image is unclear, as shown in Figure 5. However, we need a more precise visualization to measure the contact angle between the calcite surface and the water droplet. Therefore, we enhance the camera's focusing, as shown in figure 6. The left side of the image is the IRIDW camera. The rightside image is the illuminated calcite and the water droplet inside the dark hydrocarbon with better visibility to enable accurate contact angle measurement.

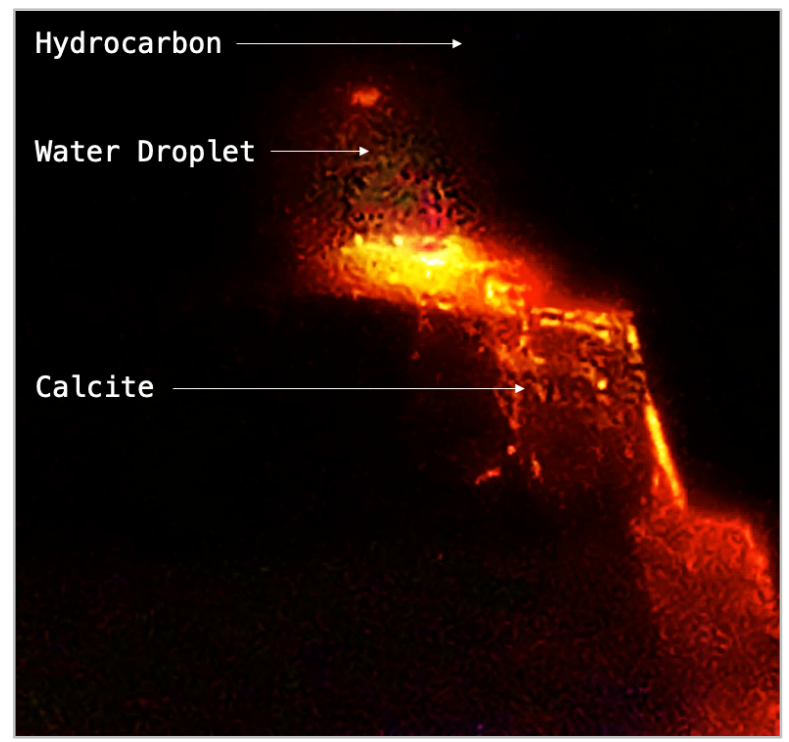

Figure 5. The first image, digitally magnified, of a water droplet on top of calcite rock, where both are inside dark hydrocarbon fluid.
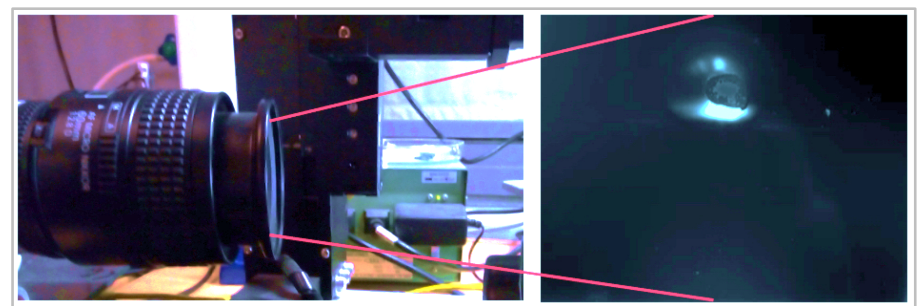

Figure 6. The camera (left) recorded enhanced visibility of a water droplet on top of calcite rock, where both are inside dark hydrocarbon fluid. 
We further enhance the visibility by making the calcite and the water droplet closer to one of the glass beakers' sides. We record another image inside the dark hydrocarbon fluid, as shown in Figure 7. We applied digital image filtering to have a more precise picture to enhance further the visibility for measuring the contact angle, as shown in Figure 8.

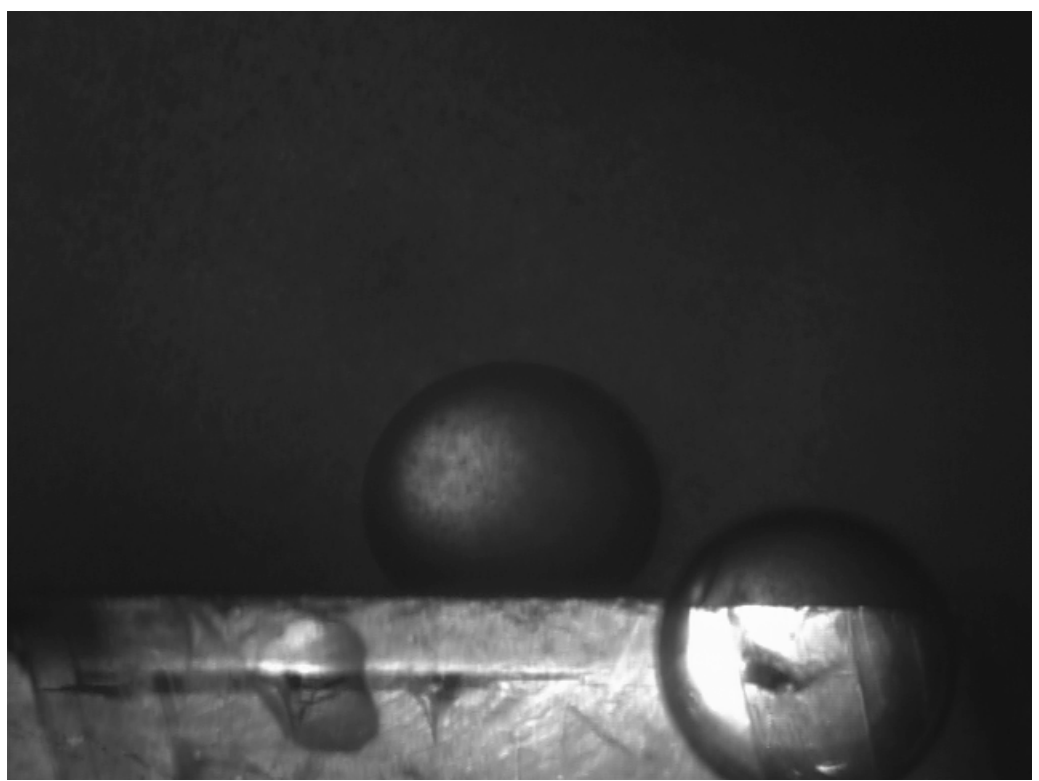

Figure 7. Enhanced the visibility of the water droplet inside the dark hydrocarbon by bringing the calcite rock closer to the side edge of the glass beaker.

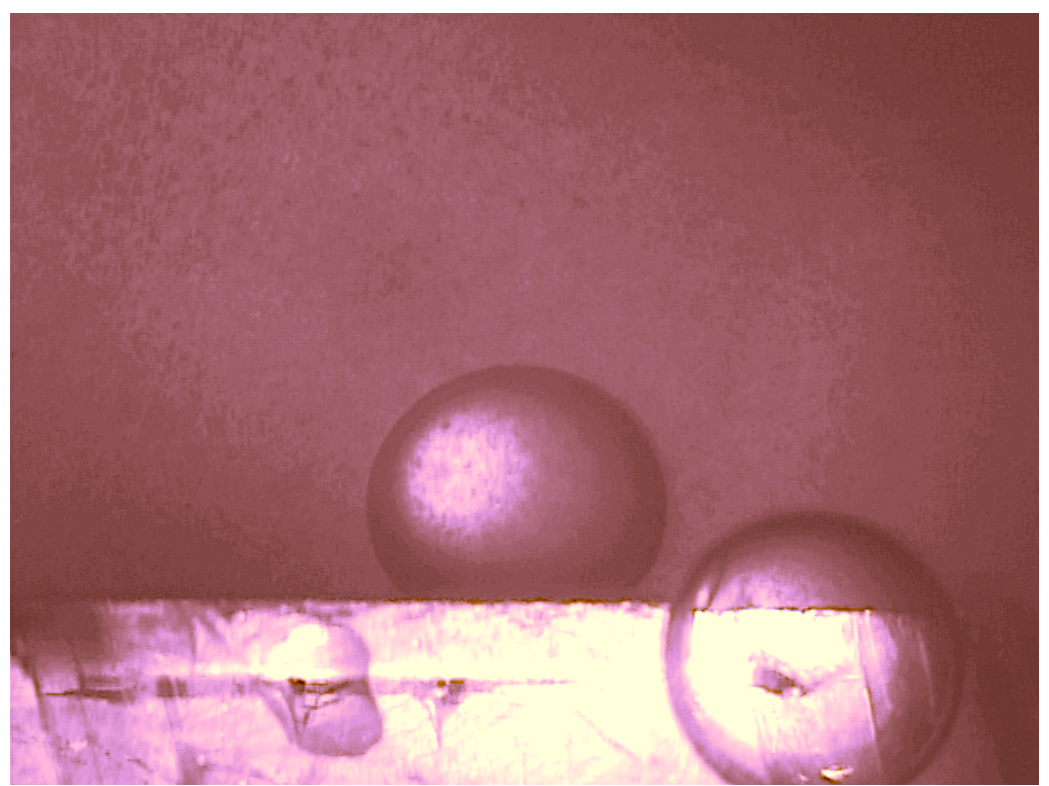

Figure 8. Image processing using digital filters to enhance the visibility of the water droplet on top of calcite inside a dark hydrocarbon.

We measure the contact angle between the calcite rock surface and the water droplet, showing $142^{\circ}$, Figure 9 . Therefore, we conclude the wettability of calcite as hydrocarbon wet because the water droplet is more than $90^{\circ}$. At the same time, 
in other literature, we see that calcite shows a water-wet behavior [44, 45]. Our work confirms that calcite has a non-preferential affinity to water or hydrocarbon; instead, calcite shows an association with the fluid that first touched the surface. We infer that unless additional mechanical forces exist (e.g., extra pressure) or electrochemical alterations [46], then the wettability of calcite holds an affinity to the first fluid.

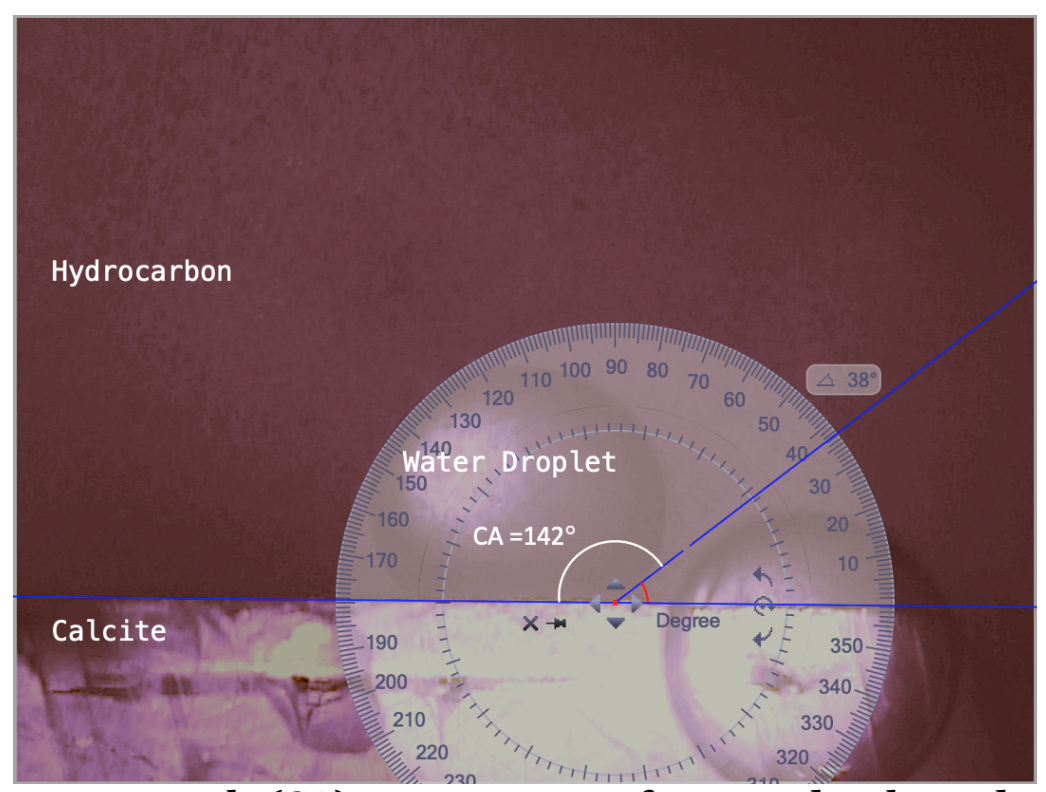

Figure 9. The contact angle (CA) measurement of a water droplet and calcite surface inside dark hydrocarbon fluid.

\section{Conclusions}

- For the first time in human history, the contact angle measurement for rock surface wettability inside dark hydrocarbon fluid is measurable using the IRIDW apparatus.

- To make the items inside dark hydrocarbon fluid visible, IRIDW introduces a second light source and provides a path for the light photons to illuminate the calcite rock crystal and the water droplet on top.

- Enhanced visibility inside dark hydrocarbon fluid is evident when the rock and water droplet is near the beaker side facing the camera.

- The calcite intrinsic wettability has no preferential to a fluid. Instead, the first fluid that touches the calcite surface governs the wettability of calcite.

\section{Authors Affiliation}

- Omar Alfarisi: Senior Engineer at the Department of Field Development of ADNOC Offshore, Adjunct Professor at the China University of Petroleum Qingdao, and Guest Lecturer at Khalifa University.

- Aikifa Raza: Research Scientist at the Department of Mechanical Engineering of Khalifa University. 
- TieJun Zhang: Professor at the Department of Mechanical Engineering of Khalifa University.

\section{Remarks}

- This paper version is a preprint for submission at the OSF Preprints library.

- $\quad$ This paper version was last updated on Jan $31^{\text {st }}, 2022$.

\section{Acknowledgment}

The authors would like to thank ADNOC, ADNOC Offshore, and Khalifa University for their support in progressing this research work. The authors would like to acknowledge the extraordinary and relentless support Dr. Hongxia Li provided during this research work.

\section{References}

1. BinAbadat, E., et al. Complex Carbonate Rock Typing and Saturation Modeling with Highly-Coupled Geological Description and Petrophysical Properties. in SPE Reservoir Characterisation and Simulation Conference and Exhibition. 2019. Society of Petroleum Engineers.

2. Khemissa, H., et al. Reservoir Characterisation of High Heterogeneous Thin Interbedding Layers. in SPE Reservoir Characterisation and Simulation Conference and Exhibition. 2011. Society of Petroleum Engineers.

3. Al-Farisi, O., et al., Well Logs: The Link Between Geology and Reservoir Performance. Abstract Geo2002, 2002. 96.

4. Rushing, J.A., K.E. Newsham, and T.A. Blasingame. Rock typing: Keys to understanding productivity in tight gas sands. In SPE Unconventional Reservoirs Conference. 2008. OnePetro.

5. Al-Farisi, O., et al. Revelation of carbonate rock typing-the resolved gap. in SPE/EAGE Reservoir Characterization \& Simulation Conference. 2009.

6. Al-Farisi, 0., et al. Carbonate Rock Type Matrix RocMat, The Ultimate Rock Properties Catalogue. in International Conference on Offshore Mechanics and Arctic Engineering. 2013. American Society of Mechanical Engineers.

7. Al-Farisi, O., M. Sassi, and D. Ouzzane. Digital Rock Typing. in InterPore2021. 2021. UK.

8. $\quad$ Alfarisi, O., et al., Digital Rock Typing DRT Algorithm Formulation with Optimal Supervised Semantic Segmentation. arXiv preprint arXiv:2112.15068, 2021.

9. Lucia, F.J., Rock-fabric/petrophysical classification of carbonate pore space for reservoir characterization. AAPG bulletin, 1995. 79(9): p. 1275-1300.

10. Lucia, F.J., Carbonate Reservoir Characterization: An Integrated Approach. 2nd Edition ed. 2007: Springer.

11. McLane, M., Sandstone: secular trends in lithology in southwestern Montana. Science, 1972. 178(4060): p. 502-504.

12. Al-Farisi, O., et al. Machine Learning for 3D Image Recognition to Determine Porosity and Lithology of Heterogeneous Carbonate Rock. in SPE Reservoir 
Characterisation and Simulation Conference and Exhibition. 2019. Society of Petroleum Engineers.

13. Landis, E.M., Capillary pressure and capillary permeability. Physiological Reviews, 1934. 14(3): p. 404-481.

14. Childs, E.C. and N. Collis-George, The permeability of porous materials. Proceedings of the Royal Society of London. Series A. Mathematical and Physical Sciences, 1950. 201(1066): p. 392-405.

15. Jones, S.C., System for measuring the pore volume and permeability of very tight core plugs and method therefor. 1986, Google Patents.

16. Mowers, T.T. and D.A. Budd, Quantification of porosity and permeability reduction due to calcite cementation using computer-assisted petrographic image analysis techniques. AAPG bulletin, 1996. 80(3): p. 309-321.

17. Trykozko, A., W. Zijl, and A. Bossavit, Nodal and mixed finite elements for the numerical homogenization of $3 D$ permeability. Computational Geosciences, 2001. 5(1): p. 61-84.

18. Nedanov, P.B. and S.G. Advani, A method to determine 3D permeability of fibrous reinforcements. Journal of composite materials, 2002. 36(2): p. 241-254.

19. Knecht, L., et al. Electrofacies and permeability modeling in carbonate reservoirs using image texture analysis and clustering tools. in SPWLA 44th annual logging symposium. 2003. Society of Petrophysicists and Well-Log Analysts.

20. Al-Farisi, O., et al. Electrical Resistivity and Gamma-Ray Logs: Two Physics for Two Permeability Estimation Approaches in Abu Dhabi Carbonates. in Abu Dhabi International Conference and Exhibition. 2004. Society of Petroleum Engineers.

21. Al Farisi, O., et al. Quantification of Fracture Permeability From Micro Resistivity Logs in Offshore Abu Dhabi Reservoir. in Abu Dhabi International Petroleum Exhibition and Conference. 2006. Society of Petroleum Engineers.

22. Ghedan, S., T. Weldu, and O. Al-Farisi. Hybrid Permeability Prediction Model for Heterogeneous Carbonate Reservoirs with Tarmat Layers Considering Different Levels of Cutoffs. in Abu Dhabi International Petroleum Exhibition and Conference. 2010. OnePetro.

23. Teklu, T.W., S.G. Ghedan, and O. Al Farisi. Hybrid Artificial Intelligence and Conventional Empirical Approach for improved Prediction of Log-Derived Permeability of Heterogeneous Carbonate Reservoir. in SPE Production and Operations Conference and Exhibition. 2010. Society of Petroleum Engineers.

24. Al-Farisi, O., et al. Permeability Determination in Fractured \& Non-Fractured Carbonate Reservoir; Using Innovative Multi Passes Analysis Approach of Basic Log Data. in SPE Reservoir Characterisation and Simulation Conference and Exhibition. 2011. Society of Petroleum Engineers.

25. Li, H., et al. Pore-Scale Experimental and Numerical Study on Permeability Characterization of Abu Dhabi Offshore Carbonate Micromodel. in Abu Dhabi International Petroleum Exhibition \& Conference. 2016. OnePetro.

26. Chhatre, S.S., et al. A Blind Study of Four Digital Rock Physics Vendor Labs on Porosity, Absolute Permeability, and Primary Drainage Capillary Pressure Data on Tight Outcrop Rocks. in Oral presentation given at the Annual Symposium of the Society of Core Analysts, Vienna, Austria. 2017. 
27. Saxena, N., et al., Estimating permeability from thin sections without reconstruction: Digital rock study of $3 D$ properties from 2D images. Computers \& Geosciences, 2017. 102: p. 79-99.

28. Wu, J., X. Yin, and H. Xiao, Seeing permeability from images: fast prediction with convolutional neural networks. Science bulletin, 2018. 63(18): p. 1215-1222.

29. Alfarisi, 0., et al., The Understanding of Intertwined Physics: Discovering Capillary Pressure and Permeability Co-Determination. arXiv preprint arXiv:2112.12784, 2021.

30. Alfarisi, O., et al., Morphology Decoder: A Machine Learning Guided 3D Vision Quantifying Heterogenous Rock Permeability for Planetary Surveillance and Robotic Functions. arXiv e-prints, 2021: p. arXiv: 2111.13460.

31. Harrison, B. and X. Jing. Saturation height methods and their impact on volumetric hydrocarbon in place estimates. in SPE Annual Technical Conference and Exhibition. 2001. OnePetro.

32. Belgaied, A., et al. Comparing the accuracy of fluid saturation derived from different logging measurements: past, present and future methodology. in Abu Dhabi International Conference and Exhibition. 2004. OnePetro.

33. Al-Marzouqi, M., et al. Enhanced Gas-Saturation Determination in Abu Dhabi Offshore Reservoirs Through Integrated Pulsed and Thermal Neutron Log Approach. in Abu Dhabi International Petroleum Exhibition and Conference. 2006. Society of Petroleum Engineers.

34. Costanza - Robinson, M.S., B.D. Estabrook, and D.F. Fouhey, Representative elementary volume estimation for porosity, moisture saturation, and air - water interfacial areas in unsaturated porous media: Data quality implications. Water Resources Research, 2011.47(7).

35. Serry, A.M., et al. Resolving Water Saturation Estimation in Thin Carbonate Reservoirs Using Resistivity Inversion. in GEO 2012. 2012. European Association of Geoscientists \& Engineers.

36. Serry, A.M., et al. Estimation of Water Saturation in Water Injector Wells, Drilled Across Tight Carbonate Formations, Using Resistivity Inversion. in SPE Reservoir Characterization and Simulation Conference and Exhibition. 2013. OnePetro.

37. Zhang, H., et al. NMR-MRI Characterization of Low-Salinity Water Alternating CO2 Flooding in tight Carbonate. in RDPETRO 2018: Research and Development Petroleum Conference and Exhibition, Abu Dhabi, UAE, 9-10 May 2018. 2018. American Association of Petroleum Geologists, Society of Exploration ....

38. Zekri, A., et al., Experimental investigation of the effect of injection water salinity on the displacement efficiency of miscible carbon dioxide WAG flooding in a selected carbonate reservoir. Journal of Petroleum Exploration and Production Technology, 2015. 5(4): p. 363-373.

39. Alfarisi, O., et al., Quantum Dipolar Coupling Thermal Correction for NMR Signal during Natural Rock Flooding by Melding Experimentation and Numerical Simulation (Th-CENS).

40. Alfarisi, O., et al., Machine Learning Guided 3D Image Recognition for Carbonate Pore and Mineral Volumes Determination. arXiv preprint arXiv:2111.04612, 2021. 
41. Li, H., et al. Pore-scale lattice boltzmann simulation of oil-water flow in carbonate rock with variable wettability. in Abu Dhabi International Petroleum Exhibition and Conference. 2015. OnePetro.

42. Al-Farisi, O., et al., Quantifying Wettability Alteration Effects on Fluid Flow Properties of Heterogeneous Porous Media, in InterPore2020. 2020.

43. Alfarisi, O., Z. Aung, and M. Sassi, Deducing Optimal Classification Algorithm for Heterogeneous Fabric. 2022, TechRxiv.

44. Lu, J.Y., et al., Direct prediction of calcite surface wettability with first-principles quantum simulation. The journal of physical chemistry letters, 2017. 8(21): p. 5309-5316.

45. Alotaibi, M.B., R. Nasralla, and H.A. Nasr-El-Din. Wettability challenges in carbonate reservoirs. in SPE Improved Oil Recovery Symposium. 2010. OnePetro.

46. Mohammed, S. and G. Gadikota, Dynamic wettability alteration of calcite, silica and illite surfaces in subsurface environments: a case study of asphaltene selfassembly at solid interfaces. Applied Surface Science, 2020. 505: p. 144516. 